\title{
DESPLAZADOS FORZADOS AMBIENTALES: UNA MIRADA DESDE LA TRAGEDIA OCURRIDA EN MOCOA (PUTUMAYO) EL 31 DE MARZO Y 01 DE ABRIL DE 2017
}

\section{Daniel Alejandro Paz Zambrano ${ }^{1}$}

RESUMEN: Este artículo pretende analizar el actuar estatal en la generación de desplazados forzados ambientales en la avenida fluvio-torrencial ocurrida en el Municipio de Mocoa el 31 de marzo y 01 de abril de 2017, con el ánimo de que se evidencie con seriedad esta categoría jurídica de protección, que subyace en gran medida de la inoperancia de la tutela efectiva del ambiente. Se requiere un compromiso real con la protección de la naturaleza partiendo del cumplimiento de la ley y la jurisprudencia que promulga nuevas categorías de entes sujetos de derechos a los ecosistemas y sus componentes naturales.

PALABRAS CLAVE: Desplazamiento forzado por desastres naturales

\section{FORCED ENVIRONMENTALLY DISPLACED: A LOOK FROM THE TRAGEDY THAT OCCURRED IN MOCOA ON MARCH 31 AND APRIL 1, 2017}

ABSTRACT: This article pretend to analyze the state action in the generation of environmental forced displaced persons in the fluvio-torrential avenue that took place in the Municipality of Mocoa on March 31 and April 1, 2017, with the aim of showing this legal category seriously. protection, which largely underlies the ineffectiveness of the effective protection of the environment. It requires a real commitment to protecting nature based on compliance with the law and jurisprudence that promulgates new categories of entities subject to rights to ecosystems and their natural components.

KEYWORDS: Forced Environmentally Displaced

\section{INTRODUCCIÓN}

Como habitante del Municipio de Mocoa en la actualidad y para los días en que sucedió la tragedia, el tema presentado reviste de una importancia profesional y personal importante; sin embargo aspiro a que de manera objetiva el primer interés prime a lo largo de las siguientes páginas. Partimos en este artículo con la definición de los desplazados forzados ambientales. "Los desplazados ambientales son damnificados por la concurrencia e interrelación de fenómenos naturales y de la intervención de la población en el medio ambiente.” (JIMÉNEZ C. y SOLEDAD J. 2011, p. 203). La preocupación mayoritaria en el estudio del cambio

\footnotetext{
${ }^{1}$ Maestrando en Derecho Público por la Universidad Surcolombiana. Integrante del grupo de investigación “Nuevas Visiones del Derecho”. Correo electrónico: da.alpazz@hotmail.es danielpaz1016@gamail.com
} 
climático y los desastres naturales, se ha concentrado en explicar las causas y consecuencias desde el punto de vista científico: variación climática, polución, concentración de gases de infecto invernadero que a su vez producen sequías, inundaciones, pérdida de biodiversidad, dificultad para la producción de alimentos, escasez de elementos naturales, daños graves a la salud humana, etc., para estos tópicos producidos por la natura con o sin injerencia humana, los expertos presentan evidencias cada vez más claras sobre la realidad de los efectos de las actividades antrópicas en el ambiente, sin embargo el análisis de las crisis sociales derivadas del deterioro ambiental o de la intervención humana en la naturaleza, como es el caso de la generación de desplazados forzados ambientales no concentra la importancia necesaria; o al menos en el ordenamiento jurídico colombiano no se hace referencia de manera clara a esta condición y no se encuentra un referente o protocolo que las autoridades competentes hayan aplicado cuando se han presentado eventos que han generado desplazamiento forzado ambiental.

La avenida fluvio-torrencial ocurrida en Mocoa el 31 de marzo y 01 de abril de 2017, dejó una gran cantidad de pérdidas de vidas humanas (más de 300 personas fallecidas) y no humanas, de bienes patrimoniales, un notable trastorno en el paisaje, deterioro en las coberturas vegetales, contaminación de las fuentes hídricas y por supuesto, desplazados forzados ambientales. Este evento producido según los expertos, por la alta pluviosidad (129 m.m. el 31 de marzo) sumado a otros factores como las altas pendientes y los movimientos en masa, fueron los detonantes de la trágica avenida fluvio-torrencial en la capital del departamento del Putumayo, localizado al sur occidente de Colombia.

Con antecedentes conocidos, ya que desde 1947 se tiene registro de eventos de avenida fluvio-torrencial, cabe cuestionar si las instituciones competentes del orden local, regional y nacional, tomaron todas las medidas que el ordenamiento jurídico ofrecía para prevenir o mitigar los efectos del fenómeno natural. Se propone entonces analizar si para el caso en concreto existía desde la Constitución de 1991 catalogada también como Constitución Ecológica e incluso antes de que entrase a regir, las herramientas normativas en materia de protección ambiental y gestión integral del riesgo de desastres, necesarias y pertinentes, que siendo aplicables integralmente hubiesen sido suficientes, adecuadas, proporcionales para para minimizar el número de víctimas y desplazados forzados ambientales y quizás también el deterioro ambiental y así con ello concluir si le asiste responsabilidad al Estado colombiano en 
el ámbito interno e internacional, por los desplazados forzados ambientales. Dicha categoría jurídica precisa ser estudiada a partir de los principios sobre desplazados forzados internos (ONU-Consejo Económico y Social-Comisión de Derechos Humanos 54 Periodo de Sesiones E/CN.4/1998/53/Add.2*11/02/1998). Por lo tanto, se pretende examinar si las autoridades competentes dieron aplicación del ordenamiento jurídico que regula entre otros, la protección del ambiente (fajas paralelas y rondas hídricas de los cauces de los ríos) y reducción del fenómeno del cambio climático, el ordenamiento ambiental del territorio y la gestión integral del riesgo de desastres.

Como medida propositiva, en este artículo se quiere verificar si existe similitud jurídica y empírica en las consideraciones que tuvo en cuenta la Honorable Corte Constitucional colombiana, en la sentencia T-622 de 2016, que reconoce a la cuenca del río Atrato (localizado en el Departamento del Chocó) y sus afluentes, como una entidad sujeto de derechos a la protección, conservación, mantenimiento y restauración a cargo del Estado y las comunidades étnicas, como medida de prevención y precaución frente al alto estado de deterioro producto de las actividades mineras legales e ilegales que se desarrollan a lo largo de su cuenca; en aras de proteger los derechos fundamentales a la vida, a la salud, al agua, a la seguridad alimentaria, al medio ambiente sano, a la cultura y al territorio de las comunidades étnicas accionantes y con ello verificar su procedencia análoga en cuanto a los efectos jurídicos sobre las fuentes hídricas que recuperaron su cauce natural en el evento de la avenida fluvio-torrencial de Mocoa y determinar si esta declaratoria hubiese alterado en alguna medida el efecto lesivo en los bienes jurídicos afectados.

Para el logro de los fines propuestos, en el presente documento se abordará desde un análisis teórico, algunas las fuentes jurídicas vinculantes para el Estado colombiano y relacionadas con los temas problemáticos. La doctrina internacional será decisiva para la comprensión del fenómeno del desplazamiento forzado ambiental y su tratamiento en otros países. Desde el ámbito nacional, se acudirá al análisis de la normatividad interna y jurisprudencia relacionada con las materias descritas. Por la complejidad y composición del problema y los resultados esperados, es imposible que la discusión teórica se realice a partir de un solo cuerpo normativo; por lo tanto, se abordará desde los siguientes grupos normativos a saber: 1) derechos de los desplazados forzados ambientales, 2) derechos del ambiente 3) gestión integral del riesgo de desastres y ordenamiento territorial. Para el caso en concreto, se analizarán 
las condiciones en las que fueron atendidas las personas en condición de desplazamiento forzado ambiental y se identificará si el Estado colombiano aplicó los principios que rigen la protección de este grupo de población; además de determinar si empleó de manera preventiva e integral los grupos normativos propuestos, para a partir de ello, definir si le asiste responsabilidad por su actuar activo u omisivo y si este fue determinante en los efectos de la tragedia ocurrida en Mocoa.

Finalmente como antes se dijo, se hará un análisis de la Sentencia de la Corte Constitucional T-622 de 2016 para proponer en el marco de los derechos de la naturaleza, la categoría de entes sujeto de derechos a la conservación, mantenimiento, restauración y no ocupación de los cauces de los ríos que se desbordaron transportando detritos, lodo y troncos produciendo la tragedia en el Municipio de Mocoa.

Este artículo pretende como objetivo general, analizar de manera integral y crítica la aplicación o no por parte del Estado colombiano de la normatividad relacionada con los desplazados forzados ambientales, la protección ambiental y efectos del cambio climático, el ordenamiento territorial y la gestión integral del riesgo de desastres y determinar si le asiste responsabilidad por el fenómeno de desplazamiento forzado ambiental producido con la avenida fluviotorrencial de Mocoa los días 31 de marzo y 01 de abril de 2017.

Como alcances secundarios, se plantea 1) describir el fenómeno y las causas del desplazamiento forzado ambiental a partir de la normatividad y doctrina existente 2) analizar en el caso de la avenida fluvio-torrencial de Mocoa el fenómeno de desplazamiento forzado ambiental. 3) Analizar si se dan los supuestos contenidos en la sentencia T-622 de 2016 de la Honorable Corte Constitucional y proponer como sujeto de derechos a la protección, conservación, mantenimiento, restauración y no ocupación, a las fuentes hídricas que recuperaron su cauce natural en el evento de la avenida fluvio-torrencial de Mocoa y por último 4) Analizar algunos de los instrumentos jurídicos adicionales que tenía disponibles el Estado colombiano para proteger los ecosistemas que tuvieron injerencia como detonantes de la avenida fluvio-torrencial del 31 de marzo y 01 de abril de 2017 en el Municipio de Mocoa 


\section{DESPLAZADOS FORZADOS AMBIENTALES-CONCEPTUALIZACIÓN}

En aras de contextualizar el concepto de desplazados forzados ambientales para el caso colombiano, no bastará con remitirnos a la doctrina o a los instrumentos internacionales especializados en la materia, es necesario interpretar la realidad de este país mega diverso: en biodiversidad, ecosistemas, climas, grupos étnicos y con un enorme potencial mineroenergético; pero además reconocer que la disputa por el control territorial tanto por actores armados del Estado como por guerrillas alzadas en armas, ha sido una de las principales fuentes que en mayor o menor medida han provocado el desplazamiento de personas por destrucción de las condiciones de vida presentes en el ambiente, con fines legítimos o ilegales; esto nos acerca a un concepto más sincero de lo que se puede llegar a entender por desplazados forzados ambientales y con ello presentar a los tomadores de decisiones en el Estado y a la comunidad en general, una mayor amplitud en el concepto, con fundamentos teóricos que les permitan reconocer las situaciones fácticas y/o jurídicas que generan este fenómeno para conjurarlo y/o prevenirlo.

En un primer momento se expondrá un concepto tradicional como el que pregona El Hinnawi quien define a este grupo poblacional como personas «que se han visto forzadas a dejar su hábitat tradicional, de forma temporal o permanente, debido a un marcado trastorno ambiental, ya sea a causa de peligros naturales y/o provocado por la actividad humana, como accidentes industriales o que han provocado su desplazamiento permanente por grandes proyectos económicos de desarrollo, o que se han visto obligados a emigrar por el mal procesamiento y depósito de residuos tóxicos, poniendo en peligro su existencia y/o afectando seriamente su calidad de vida» (El Hinnawi , 1985 p. 4).

En sintonía con la definición expuesta, se presenta el criterio institucional; de acuerdo con JIMÉNEZ C. y SOLEDAD J. (2011, p. 203), La Organización Internacional de las Migraciones (OIM) define los migrantes (y no desplazados) por causas ambientales, como «las personas o grupos de personas que, por motivo de cambios repentinos o progresivos en el medio ambiente, que afectan adversamente su vida o sus condiciones de vida, se ven obligados a abandonar sus lugares de residencia habituales, o deciden hacerlo, bien sea con carácter 
temporal o permanente, y que se desplazan dentro de sus propios países o al extranjero» (OIM; 2007: 3);

Nuestro concepto retoma en buena medida estas dos nociones, pero como antes se dijo y sin ánimos de mayores pretensiones, se introduce un planteamiento que parte de la realidad colombiana, caracterizada por una enorme riqueza ecosistémica, diversidad cultural y por las condiciones de conflicto armado interno que se involucran de manera negativa en la generación de desplazamiento forzado por cuestiones ambientales. Consideramos que los desplazados forzados ambientales son las personas o comunidades que abandonan los lugares que habitan (temporal o permanentemente) por transformaciones negativas en el ambiente causadas de forma natural o por cualquiera de los siguientes eventos:

\subsection{ASOCIADOS A MANIFESTACIONES NATURALES.}

En esta categoría se encuentran todos aquellos eventos de la naturaleza que se entienden producidos de manera espontánea por aquella, como por ejemplo, las erupciones volcánicas, terremotos, huracanes, tsunamis, etc., donde si bien no es posible predecir con exactitud las dimensiones de la ocurrencia de un siniestro, la aplicación de sistemas de alerta temprana, la planificación reflexiva en el ordenamiento ambiental del territorio, la observancia de los principios de prevención y precaución en la gestión de riesgos de desastres, constituyen herramientas pertinentes para que la toma de decisiones sobre la forma de afrontar el desastre natural, sea posible evitando la menor afectación a la vida, integridad y salud de las personas. Según lo revela el último informe del Consejo Noruego para Refugiados, en el 2014 más de 19 millones de personas tuvieron que abandonar sus hogares por inundaciones, tormentas y terremotos, que significa una cifra hasta cuatro veces superior a las migraciones por conflictos armados. El Panel Intergubernamental del Cambio Climático (IPCC) asegura que para el año 2050 la cifra de desplazados ambientales puede alcanzar los 250 millones. $^{2}$

\footnotetext{
${ }^{2}$ Movilidad Humana, Desastres Naturales y Cambio Climático en América Latina de la Comprensión a la Acción: Grupo de Trabajo "Migración Ambiental en Latinoamérica” de las redes sectoriales RED-LAC UND RED GADerALC de la Deutsche Gesellschaft für Internationale Zusammenarbeit (GIZ) GmbH, por encargo del Ministerio Federal de Cooperación Económica y Desarrollo. Noviembre 2017
} 


\subsection{NDUCIDOS POR EL EFECTO DE LAS ACCIONES HUMANAS EN LA NATURALEZA.}

\subsubsection{ASOCIADOS A LOS EFECTOS DEL CAMBIO CLIMÁTICO.}

Cambios en las niveles de precipitaciones que generan inundaciones, avenidas torrenciales, torrenciales, deshielo de los polos, sequías etc, son fenómenos inducidos por la presión que producen las actividades antrópicas en la naturaleza; en su mayoría producto de la aplicación de modelos de desarrollo basados en la acumulación de capital sobre la base de la explotación irracional de los recursos naturales.

\subsubsection{GENERADOS POR DESASTRES INDUSTRIALES, O CONTAMINACIÓN INDUCIDA.}

Aquellos eventos en que dadas ciertas condiciones, por inobservancia de protocolos de seguridad, inaplicación de una norma técnica o un actuar premeditado, se genera un rompimiento en el funcionamiento normal de la fuente potencial de contaminación y se producen consecuencias en el ambiente, que ameritan la movilización de las personas en aras de prevenir y/o salvaguardar intereses como la salud, la vida y la integridad. Por otra parte puede ocurrir que en contravía de lo establecido en el instrumento jurídico de control (licencia, permiso, autorización o concesión), o en ausencia de aquél; el particular mediante un accionar premeditado descargue sobre el ambiente elementos que lo transforman y que generan efectos negativos en el ecosistema. En el caso colombiano este tipo de conductas están catalogadas como delitos y les asiste una pena de prisión y una multa, sin perjuicio del respectivo trámite sancionatorio ambiental. La Ley 599 de 2000 “Código penal” define en los siguientes términos: “Artículo 332. Contaminación ambiental. Modificado por el art. 34, Ley 1453 de 2011. El que, con incumplimiento de la normatividad existente, contamine el aire, la atmósfera o demás componentes del espacio aéreo, el suelo, el subsuelo, las aguas o demás recursos naturales en 
tal forma que ponga en peligro la salud humana o los recursos fáunicos, forestales, florísticos o hidrobiológicos, incurrirá, sin perjuicio de las sanciones administrativas a que hubiere lugar, en prisión de tres (3) a seis (6) años y multa de cien (100) a veinticinco mil (25.000) salarios mínimos legales mensuales vigentes.

La pena se aumentará de una tercera parte a la mitad cuando la conducta se realice con fines terroristas, sin que la multa supere el equivalente a cincuenta mil salarios mínimos legales mensuales vigentes."

\subsubsection{OCASIONADOS EN EL MARCO DE ACTIVIDADES ILEGALES O CRIMINALES.}

La disputa del control territorial por parte de organizaciones criminales para la producción, procesamiento y comercio de estupefacientes, la explotación ilegal de madera, el comercio ilegal de fauna silvestre, los atentados terroristas a la infraestructura petrolera, la minería criminal, el acaparamiento de tierras etc., son acciones catalogadas como delito en la mayoría de los estados; las complejas organizaciones criminales son de difícil control y contrarresto por parte de las autoridades, quienes pierden control territorial y soberanía frente a los llamados Para-Estados (territorio de un mismo Estado gobernado bajo las reglas y condiciones impuestas por las organizaciones criminales y sobre el desconocimiento absoluto del ordenamiento jurídico). Las acciones delictivas generan un trastorno y contaminación del ambiente que fuerza el desplazamiento de poblaciones e incluso de comunidades étnicas y nómadas a lugares que les brinden seguridad personal, alimentaria y el goce de un ambiente sano.

\subsubsection{DEFICIENTE PLANIFICACIÓN Y ORDENAMIENTO AMBIENTAL DEL TERRITORIO.}


Corresponde a todos aquellos casos en que el actuar permisivo u omisivo de las autoridades encargadas del ordenamiento territorial, permiten o auspician el poblamiento de zonas de alto riesgo y exponencialmente ponen en peligro la vida e integridad personal; como por ejemplo, cuando en dichas zonas, pese al conocimiento técnico del riesgo, se toman decisiones administrativas tales como: otorgamiento de licencias de construcción, construcción de obras para suministro de servicios públicos domiciliarios, modificación del uso del suelo en los instrumentos de ordenamiento territorial. De manera permisiva cuando no controlan su ocupación con medidas policivas, no aplican o hacen cumplir la normatividad referente a la protección de las fajas paralelas de los ríos o su ronda hídrica, desconocen el ordenamiento jurídico ambiental en materia de prevención y precaución y así mismo las disposiciones referentes a la gestión integral de riesgo de desastres.

\section{POR DECISIONES ESTATALES EN AMPARO DEL ORDENAMIENTO JURÍDICO O EN UNA POLÍTICA PÚBLICA.}

\subsection{GENERADOS POR LA REGULACIÓN ESTATAL DE LOS RECURSOS NATURALES RENOVABLES Y NO RENOVABLES.}

De forma genérica se los conoce o los autores los definen como desplazados forzados por proyectos de desarrollo. En este punto es importante recalcar que esta modalidad de desplazamiento en cierta medida está autorizada en una norma jurídica (licencia, permiso, concesión o autorización) que permite desarrollar la actividad de explotación de los recursos naturales. Las condiciones en cuanto a cantidades y dimensiones de las obras o actividades a ejecutar, implican la transformación del paisaje y de los modos tradicionales de subsistencia o la contaminación de las fuentes hídricas o de la atmósfera y ponen en riesgo la salud, la vida y el derecho a un ambiente sano, haciendo incompatible la coexistencia de personas en áreas de influencia del proyecto, obra o actividad, como sería el caso de la construcción de embalses, hidroeléctricas, vías, rellenos sanitarios etc., y la explotación minero-energética que requiere de la transformación de áreas extensas para su extracción. Si bien en estos eventos existe en teoría un manejo socio-predial que el titular del acto administrativo debe cumplir, ello no 
implica que en últimas y con el amparo estatal, se genere desplazamiento forzado ambiental y que las movilizaciones de personas o comunidades tengan su fuente en una autorización estatal a un particular o al mismo Estado.

\subsection{EN EL MARCO DE UN CONFLICTO ARMADO.}

En la ejecución de las acciones y políticas para afrontar las consecuencias del conflicto armado, el Estado recurre a medidas radicales de contención que generan graves trastornos en el ambiente, como por ejemplo la confrontación bélica con armamento no convencional, la instalación de campamentos y ocupación temporal o permanente de zonas de abastecimiento de recursos, la aspersión aérea con glifosato para controlar los cultivos para procesamiento de sustancias ilícitas etc., no solo el temor del combate armado propicia el desplazamiento de comunidades, sino además la destrucción de los medios de vida, que debido a las operaciones de combate impiden el desarrollo de las actividades cotidianas de subsistencia.

\subsection{DEBIDO A MEDIDAS ESTATALES DE PROTECCIÓN DEL AMBIENTE.}

En esta subcategoría se encuentran todos aquellos casos en que por el interés general y deber de protección del ambiente y las área de importancia ecológica, las Autoridades Estatales requieren tomar medidas que involucran restricciones al ejercicio de la propiedad privada y que fuerzan al propietario a transferir su dominio al Estado, voluntariamente o de manera forzada y a desplazarse a otro lugar sin restricciones de uso de carácter ambiental; como sería en los caso de constitución, ampliación, recategorización de áreas protegidas, constitución de parques naturales para la conservación de la biodiversidad y ecosistemas, establecimiento de planes ordenamiento y manejo de cuencas, rondas hídricas y en general de cualquier medida con finalidad de protección ambiental, que si bien atiende al logro de un interés superior y general, si las medidas son de restricción absoluta para el desarrollo de actividades económicas incompatibles con la figura de protección, e impiden la coexistencia de personas y sus modos tradicionales de uso de la tierra para su sustento, entonces estamos frente a un desplazamiento 
propiciado por el mismo Estado pero con la finalidad de garantizar la protección de áreas de especial importancia ecológica.

Enunciados los eventos que consideramos pueden dar lugar generación de desplazados forzados ambientales, se concretizará lo enunciado en la tragedia ocurrida por la avenida fluviotorrencial en el Municipio de Mocoa, capital del Departamento del Putumayo en el año 2017.

\section{AVENIDA TORRENCIAL MOCOA-DESCRIPCIÓN}

La tragedia ocurrida en Mocoa el 31 de marzo y el 01 de abril de 2017 ha dejado muchas enseñanzas tanto a los habitantes del municipio como a las autoridades del orden territorial y nacional. Una cantidad de pérdidas de vidas humanas (más de 300 personas fallecidas) y no humanas, de bienes patrimoniales y además un notable trastorno en el paisaje, son las secuelas de este evento producido según los expertos, por la alta pluviosidad (129 m.m. el 31 de marzo), lluvias intensas en un periodo de tiempo, sobresaturación de suelos, movimientos en masa de diferente tipo y arrastre intempestivo de grandes cantidades de materiales, a lo largo de los cauces naturales de la Q. Taruca, Q. Taruquita, Q. San Antonio, Conejo, Almorzadero Rio Sangoyaco y rio Mulato. (CORPORACIÓN PARA EL DESARROLLO SOSTENIBLE DEL SUR DE LA AMAZONIA [CORPOAMAZONIA] 2017 p. 7)

Si bien el 31 de marzo las precipitaciones fueron altas, no es la primera vez que en el Municipio de Mocoa llueve con tanta intensidad, se tienen registros de anteriores precipitaciones con inclusive mayor entidad, por lo que el evento de variabilidad climática no sería el único detonante. Sobre las casusas del desastre surgieron varias hipótesis, como por ejemplo, que el evento fue producido por la deforestación en las partes altas de los nacimientos de las fuentes hídricas, o producto de actividades mineras ilegales, e incluso se llegó a afirmar que miembros disidentes de las FARC E.P., fueron los que atentaron produciendo el advenimiento de la masa de tierra y rocas.

Como lo expone CORPOAMAZONIA "La pérdida de coberturas no es un factor determinante para el desarrollo de la Avenida Fluvio Torrencial, toda vez que el 70\% de los sectores con deslizamientos tenían cobertura de bosque denso, intervenido, ripario y 
fragmentado. La Avenida Fluvio Torrencial por su parte, generó pérdidas de coberturas naturales (bosques, herbazales y vegetación secundaria) que llegaron a las 458,2 hectáreas, de las cuales 274,6 son de bosque denso; mientras que las pérdidas de cobertura natural por cambio de uso de suelo de bosque denso a pastos entre 2012-2014 fueron de 2,7 hectáreas; esto representa que entre los movimientos en masa y la avenida fluvio torrencial se perdieron en 4 horas 100 veces más cobertura de bosque que la pérdida generada por cambio antrópico de cobertura.” (CORPOAMAZONIA 2017 p. 8)

Se tiene registro de diez eventos de avenida torrencial: A) Localización: Río Mulato. Fecha: 1947 con daños en viviendas, animales domésticos y cultivos. B Localización: Río Mocoa. Fecha: 1960, muerte de tres personas y de ganado vacuno. C) Localización: Mocoa, Río Mulato. Fecha: 1971, Cinco viviendas con daños y pérdida de animales domésticos. D) Localización: Río Sangoyaco. Fecha: 1972, Muerte de tres personas. E) Localización: El Pepino. Fecha: 1979, Destrucción de puente vía Mocoa-Pasto, destrucción viviendas, pérdida de parque automotor, ocho muertos. F) Localización: Zona urbana de Mocoa, ríos Mulato y Sangoyaco. Fecha: 1989, Destrucción de cuatro viviendas barrio 17 de Julio, remociones en masa detrás de Caja Agraria. G) Localización: Zona urbana, ríos Taruca, Mulato, Sangoyaco y Mulato. Fecha: 1994, Sectores inundados como la plaza de mercado y barrios Miraflores, Pablo VI y Naranjito; destrucción parcial del puente peatonal sobre el río Sangoyaco. H) Localización: San José del Pepino. Fecha: 1996, Un muerto. I) Localización: Zona urbana Mocoa, río Mulato. Fecha: 1997, Una niña muerta, una vivienda averiada, daños menores en varias viviendas. J) Localización: Ríos Mocoa, Sangoyaco, Mulato, Rumiyaco y Pepino. Fecha: 1998, Seis viviendas afectadas en el Estadero Caliyaco, seis viviendas en el barrio Las Américas, pérdida de cultivos de caña en la vereda Rumiyaco, pérdida de 10 hectáreas de pastizales y ganado vacuno. (CORPOAMAZONIA 2003 p. 12)

Los estudios elaborados por la Autoridad Ambiental con jurisdicción en el Municipio de Mocoa y recomendaciones comunicadas al Municipio como autoridad principal y ordenador del territorio, sobre la posibilidad de la ocurrencia de un desastre natural y la necesidad de tomar medidas preventivas, quedó plasmada entre otros en el documento técnico denominado: “Análisis de amenazas y vulnerabilidad geológica en la cuenca de la quebrada Taruca y Sangoyaco para el área rural, sub-urbana y urbana de la población de Mocoa departamento del Putumayo” que dan cuenta de la necesidad de tomar medidas afirmativas y contundentes para 
evitar en cierto grado los efectos de la producción de la tragedia. El estudio concluye con la siguiente recomendación: “Teniendo en cuenta los grandes bloques encontrados en la parte distal del abanico puede deducirse que algunas áreas de la zona delimitada como amenaza baja no están exentas de sufrir un evento o eventos de gran magnitud; por lo que se recomienda tomar medidas preventivas como la concientización a la comunidad por el peligro que representa estas quebradas, y la importancia de proteger y conservar los corredores o rondas de las quebradas para minimizar la energía de un posterior evento. (CORPOAMAZONIA 2013 p. 17)

Así mismo en el 2014 en un estudio contratado por varias instituciones denominado “Estudio detallado de amenaza de inundación con referencia a una máxima avenida de las quebradas Taruca y Conejo en el municipio de Mocoa, departamento del Putumayo” expone la necesaria contemplación de reubicación de parte del municipio teniendo en cuenta lo decantado en el estudio, se asevera que: "La zonificación del riesgo implica cualificar si su naturaleza es mitigable o no mitigable a través de las diferentes medidas que se puedan plantear. Es por eso que dentro del área de estudio donde el nivel es alto para los barrios La Gaitana, San Fernando y San Miguel 0017, 0021 a 0028, 0032, 0033, 0038, 0039, 0047, 0048 de debe propender a la reubicación, independientemente de la efectividad de las medidas estructurales planteadas.” (PEÑA 2016 p. 21)

Ante los fallidos o negligentes actos de las autoridades para evitar el poblamiento de aquellas zonas afectadas e identificadas con estudios técnicos como áreas de alto riesgo; la inexperiencia y falta de conocimiento en la manera de atender estos eventos -ligados fenómenos naturales y de variabilidad climática-, surge la necesidad de establecer las condiciones en las que se encuentran estas personas, no solo desde la óptica de su categorización como damnificados -que llevó a adoptar la declaratoria de calamidad pública para el manejo y atención del desastre, sino que atendiendo a la génesis de los factores detonantes de la tragedia, entre ellos el más determinante -la variabilidad climática-o las manifestaciones ambientales, podemos entonces reclamar el status de protección especial a estas sujetos en calidad de desplazados forzados ambientales y con ello, generar no solo conciencia de los efectos del cambio climático y los fenómenos naturales sino propender por unas medidas de atención y protección más apropiadas a estas personas, desde las instancias nacionales y/o internacionales. 
Vistos los anteriores antecedentes, cabría pensar si ¿Es posible desde el punto de vista jurídico, considerar a los damnificados de la tragedia ocurrida en Mocoa el 31 de marzo y el 01 de abril de 2017, como desplazados forzados medioambientales y con ello derivar responsabilidad al Estado colombiano en las instancias del nivel nacional e internacional? Desde el punto de vista legal, la Corte Interamericana ha destacado la obligación del Estado de evitar el desplazamiento de personas cuando existan indicaciones previas de que eso podría ocurrir. Del mismo modo, la jurisprudencia comparada indica que si un Estado no toma medidas preventivas frente a la gestión del riesgo de desastres, podría ser responsable de los daños ocasionados y de las violaciones de derechos de la población afectada ${ }^{3}$. Bajo este criterio entonces es factible concluir que el principio de responsabilidad estatal por daños a particulares y violación de derechos humanos es razón para que se derive de esta comunidad jurídica organizada, el respectivo juicio de reproche y se le condene a reparar todos los daños causados a las víctimas, sus familiares, los desplazados y el medio ambiente.

A renglón seguido se expone un resumen de la sentencia T-622 de 2016 por la cual ante un deterioro ambiental dela cuenca del río Atrato y sus afluentes, producto de explotaciones mineras legales e ilegales, la Corte Constitucional le reconoce como ente sujeto de derechos a la conservación, protección y restauración a cargo del Estado y las comunidades.

\section{ANÁLISIS DE LA SENTENCIA T-622 de 2016}

La sentencia T-622 de 2016 de la Honorable Corte Constitucional, es desde el punto de vista del derecho constitucional y de los derechos de la madre naturaleza, una sentencia hito en la compresión de la relación naturaleza-humanos para el caso colombiano; instalando en un caso concreto la teoría biocéntrica como nuevo paradigma para lograr la pervivencia de todas las especies que habitamos el planeta; sin pretender en un inicio lograr un fallo de tal magnitud, la Corte inicia el conocimiento de la acción de tutela en sede de revisión; partiendo de los siguientes antecedentes procesales:

\footnotetext{
${ }^{3}$ Movilidad Humana, Desastres Naturales y Cambio Climático en América Latina de la Comprensión a la Acción: Grupo de Trabajo "Migración Ambiental en Latinoamérica” de las redes sectoriales RED-LAC UND RED GADerALC de la Deutsche Gesellschaft für Internationale Zusammenarbeit (GIZ) GmbH, por encargo del Ministerio Federal de Cooperación Económica y Desarrollo. Noviembre 2017
} 
1. Las comunidades étnicas que habitan la cuenca del río Atrato (Departamento del Chocó, occidente colombiano) reclaman la protección de sus derechos fundamentales a la vida, a la salud, al agua, a la seguridad alimentaria, al medio ambiente sano, a la cultura y a su territorio ancestral, que se ven menoscabados o vulnerados por los aprovechamientos ilegales de minería, que utiliza métodos contaminantes como el mercurio en enormes cantidades para separar el material. Además de la explotación maderera ilegal que acaba con el hábitat de especies de animales y plantas.

2. La contaminación del río Atrato repercute en la calidad del agua para consumo y abastecimiento, para el desarrollo de actividades agrícolas y pesqueras, medios de sustento diario de las comunidades.

3. Organizaciones ambientales y de derechos humanos coadyuvan la acción de tutela en contra de la Presidencia de la República, el Ministerio de Medio Ambiente y Desarrollo Sostenible y otros, para que se amparen los derechos tutelados y en consecuencia se ordene al gobierno la solución estructural de la crisis que afrontan estas comunidades en la cuenca del río Atrato, sus afluentes y territorios aledaños

4. En primera instancia, el conocimiento del amparo solicitado le corresponde al Tribunal Administrativo de Cundinamarca, quien niega las pretensiones señalando en síntesis que existe otro medio judicial más idóneo para proteger los derechos colectivos al ambiente sano, como sería la acción popular.

5. En impugnación del fallo de instancia le corresponde conocimiento al Consejo de Estado (órgano de cierre de la jurisdicción contencioso administrativa). Este a su vez confirma la decisión del Tribunal Administrativo de Cundinamarca que declaró improcedente la acción de tutela como medio de amparo de los derechos reclamados vulnerados.

6. En sede de revisión la Corte Constitucional avoca conocimiento y presenta los siguientes temas que desarrolla mediante un análisis argumentativo integral para fundamentar el amparo solicitado y construir la regla aplicable a este caso concreto:

- Protección especial de los ríos, los bosques, las fuentes de alimento, el medio ambiente y la biodiversidad. El derecho fundamental al agua, la protección de la naturaleza y la seguridad alimentaria. 
- La relevancia constitucional de la protección de los ríos, los bosques, las fuentes de alimento, el medio ambiente y la biodiversidad.

- Derecho a la supervivencia física, cultural y espiritual de las comunidades étnicas. Derechos territoriales y culturales.

- La minería y sus efectos sobre el agua, el medio ambiente y las poblaciones humanas: principio de precaución en materia ambiental y en salud. El caso de las comunidades étnicas del Chocó que habitan la cuenca del río Atrato.

Solución del caso: la Corte encuentra que las entidades demandadas son responsables por la vulneración de los derechos fundamentales al agua y a la seguridad alimentaria de las comunidades étnicas accionantes y por la contaminación del río Atrato y sus afluentes producida por el desarrollo de actividades de explotación minera ilegal en la región, por su conducta omisiva al no proveer una respuesta institucional idónea y efectiva para atender y dar solución a la problemática denunciada.

En aplicación del principio de precaución en materia ambiental, la Corte señala los objetivos de i) prohibición de uso de sustancias como el mercurio en el desarrollo de actividades mineras (legales o ilegales) y ii) declarar que el río Atrato es sujeto de derechos que implican su protección, conservación, mantenimiento y en el caso concreto, restauración. Dispone que el Estado colombiano ejercerá la tutoría y representación legal de los derechos del río en conjunto con las comunidades étnicas que habitan su cuenca.

Para el caso de Mocoa, ¿es posible considerar la aplicación análoga de este postulado jurisprudencial que reconoce a una fuente hídrica y a sus afluentes como sujeto de derechos a la protección, conservación y mantenimiento a cargo del Estado y de las comunidades? partiendo del supuesto de que no se trata de un hecho contaminante por el accionar ilegal o legal de exploración irracional de su cauce, sino que tiene que ver con la ocupación ilegal del mismo y su ronda hídrica de las quebradas Taruca, Taruquita, Almorzadero, y los Ríos Sangoyaco, Mulato y Mocoa que recuperaron su cauce natural con la avenida fluvio torrencial del 31 de marzo y 01 de abril de 2018, consideramos que por la trascendencia de la tragedia y el estado de ilegalidad de ocupación de la faja paralela de que trata el artículo 83 del Código de Recursos Naturales Decreto-Ley 2811 de 1974 que establece “Salvo derechos adquiridos por particulares, son bienes inalienables e imprescriptibles del Estado: d.- Una faja paralela a la línea de mareas máximas o a la del cauce permanente de ríos y lagos, hasta de treinta metros 
de ancho;” debe considerarse clamar la aplicación de la ratio decidendi de la Sentencia T-622 de 2016 en aras de garantizarle a estas fuentes hídricas los mismos derechos de que goza el Río Atrato en el Chocó.

La responsabilidad de las entidades estatales por acción (permitiendo poblar zonas conceptuadas como de riesgo, en faja de protección de las fuentes, suministrando obras para la instalación servicios públicos en dichas áreas, otorgando licencias de construcción, promoviendo con acciones activas la ocupación y poblamiento de estas zonas declaradas en riesgo) y de forma omisiva (desconociendo el postulado de protección absoluta de las fajas paralelas a los cauces, no ejerciendo control policivo de los asentamientos ilegales que se fueron asentando permisivamente por las autoridades locales, inaplicación de la normatividad que regula la prevención de riesgos de desastres y de ordenamiento territorial). Si bien como antes se dijo no estamos ante a un caso de contaminación de una fuente hídrica como sucede en el río Atrato y sus afluentes, pero sí frente a la ocupación ilegal de sus cauces y rondas hídricas, si contemplamos estas fuentes como sujetos de derecho a la protección, conservación restauración y prohibición de ocupación de sus rondas, por antonomasia una de las principales acciones de las autoridades y las comunidades será proteger su cauce natural y su ronda hídrica, con ello se prevendría que ante una nueva avenida torrencial o fluvio-torrencial se afecten derechos fundamentales como la vida, integridad personal, servicio de agua para consumo, ambiente sano y por supuesto la generación de desplazamiento forzado ambiental; derechos en su mayoría tutelados con la sentencia T-622 de 2016 de la Corte Constitucional.

Como apunte adicional a la sentencia referida, la Corte en el análisis de procedencia de la acción de tutela para la protección del derecho al medio ambiente sano de las comunidades, se refiere de manera tangencial al desplazamiento de los grupos y comunidades étnicas por cuestiones del deterioro ambiental de la cuenca y afluentes del río Atrato,. Indica este hecho en los siguientes términos: "se entiende que contar con un medio ambiente sano es una condición necesaria para garantizar otros derechos fundamentales de las comunidades étnicas, como son: la identidad colectiva y la integridad cultural.

Cuando las condiciones de deterioro ambiental del territorio no permiten a los miembros de una comunidad étnica contar con bienes individuales básicos como la salud y la integridad personal, estos se ven forzados a desplazarse a otras partes del país donde dichos derechos sí estén garantizados, o al menos no amenazados de forma directa. Por otra parte, 
este fenómeno del desplazamiento no sólo afecta las vidas de los individuos que parten de su tierra, también destruye el tejido social que mantiene unidas a las comunidades, aquel que permite mantener las tradiciones culturales y los diferentes modos de vida que son, en últimas, los que mantienen la vigencia del carácter pluralista del Estado colombiano, principio fundamental consagrado en el artículo $1^{\circ}$ de la Carta. Por lo tanto, la protección del medio ambiente sano de las comunidades negras adquiere especial relevancia desde el punto de vista constitucional, dado que es una condición necesaria para garantizar la vigencia de su estilo de vida y de sus tradiciones ancestrales.”

Como puede leerse, la Corte evidencia la posibilidad de desplazamiento de las comunidades étnicas por cuestiones del deterioro ambiental, lo que genera un rompimiento en los lazos comunales y las relaciones costumbristas; en la mayoría de casos estos grupos arriban a las ciudades capitales engrosando las cadenas de miseria y exclusión; son víctimas de delitos como explotación y violencia sexual, usados para el comercio al menudeo de sustancias prohibidas, ganchos ciegos para el cometimiento de delitos y en general, no gozan de todos los derechos que a los locales se les garantiza. No encuentran en el destino receptor las condiciones mínimas que permitan su supervivencia debido a que no existe preparación por parte de los organismos del Estado para responder a las necesidades de los desplazados forzados ambientales; el conflicto armado si bien nos ha preparado para admitir desplazados por la violencia en todo el territorio nacional, el desplazado por cuestiones del deterioro ambiental y del entorno, no recibe el tratamiento a la luz de los principios de los desplazados forzados internos.

Para el caso de los desplazados forzados ambientales de Mocoa, en principio consideramos que el gobierno nacional no los ha calificado como tales, únicamente lo ha hecho como damnificados por el desastre natural; en un análisis crítico de la forma cómo el Estado ha sorteado la crisis humanitaria de dichas personas, podremos decir que las acciones han sido lentas y únicamente para atender la tragedia; se han otorgado auxilios temporales de arrendamiento; se están construyendo 100 viviendas para algunos de los damnificados, se ha asistido con auxilios funerarios y remesas y pequeños apoyos para la reactivación del comercio, pero ¿es eso suficiente? A la luz de los principios de los desplazados forzados internos no se refleja una postura estatal que indique por ejemplo: ¿cuántas personas se han desplazado a otros municipios dentro del Departamento o fuera de éste? ¿Se han desplazado a países frontera como 
el Ecuador? ¿Se les ha tratado de manera igualitaria y asegurado el acceso a todos los derechos sin discriminación? ¿Si son desplazados forzados ambientales, se les ha explicado la imposibilidad de retornar y ocupar los lugares que habitaban por considerarse inseguros y de alto riesgo?

\section{INSTRUMENTOS NORMATIVOS ADICIONALES PARA LA PREVENCIÓN DE LOS DESPLAZADOS FORZADOS AMBIENTALES EN EL CASO DE MOCOA.}

Consideramos que adicionalmente al aporte constituido por la decisión de la Corte Constitucional y la posibilidad de su aplicación análoga para el caso de las quebradas Taruca, Taruquita, Almorzadero, y los Ríos Sangoyaco, Mulato y Mocoa, el concepto de protección de las fajas paralelas a los cauces de los ríos consagrado en el Código de Recursos Naturales Decreto-Ley 2811 de 1974, es uno de los principales elementos no tenidos en cuenta por las autoridades a la hora de ordenar ambientalmente el territorio y prevenir con ello los impactos por inundaciones y/o avenidas torrenciales. Este cuerpo normativo establece en su artículo 83 que "Salvo derechos adquiridos por particulares, son bienes inalienables e imprescriptibles del Estado:

d.- Una faja paralela a la línea de mareas máximas o a la del cauce permanente de ríos y lagos, hasta de treinta metros de ancho;” en interpretación armónica con el postulado del artículo 79 de la Constitución Política de Colombia que le impone al Estado el deber de proteger la diversidad ecológica y las áreas de importancia estratégica- como las rondas hídricas-, hubiesen sido pertinentes para por lo menos prevenir en cierta medida los efectos dañosos de la avenida fluvio torrencial prohibiendo su ocupación o no facilitándola.

Por otra parte era necesario acudir a los principios generales del derecho ambiental como el de prevención y precaución, consagrados en la Ley 99 de 1993 (Ley que establece el Sistema Nacional Ambiental), máximas que obligan al estado a adoptar decisiones antes de la ocurrencia de cualquier situación que ponga en riesgo la vida, integridad y el ambiente y/o adoptarlas sin tener la plena certeza de sus causas y efectos. De haberse dado aplicación, a estos postulados, en primer lugar se hubiese evitado no el desastre natural, pero sí el cuantioso número de 
víctimas y desplazados forzados medioambientales; en segundo lugar, no se tendría afectación a los derechos conculcados en las magnitudes presentadas, por cuanto en las zonas afectadas es indiscutible que nunca debieron existir poblamientos humanos, atendiendo al concepto de ronda hídrica, determinantes ambientales, ecosistemas de especial importancia ecológica y a los principios antes mencionados (prevención, precaución) y a los de pro homine y pro ambiente.

El modelo de gestión integral de riesgo de desastres consagrado en la Ley 1523 de 2012 contiene las medidas preparatorias y preventivas para precisamente, evitar que los desastres naturales incidan negativamente en la integridad personal, la vida, los bienes y el ambiente. Se recalca la importancia en el tema de la prevención como la medida más pertinente para evitar daños; no obstante, la norma no atiende de manera precisa el fenómeno de desplazamiento forzado ambiental, sencillamente porque no hace alusión alguna al mismo. Sin embargo corresponde mencionar que la implementación del Sistema Nacional de Gestión de Riesgos de Desastres no cuenta con presupuesto determinado, el mismo se construye por la voluntad política y las gestiones de las entidades gubernamentales y los apoyos de ONG y países o particulares extranjeros, lo que redunda en que las acciones posteriores a los eventos estén supeditadas a la consecución y gestión de recursos económicos.

\section{CONCLUSIONES.}

1. La primera conclusión es que existe un total desconocimiento del fenómeno y las causas del desplazamiento forzado ambiental por parte de las autoridades administrativas y judiciales, lo que se traduce en una inobservancia de los principios y derechos que les asisten a estas personas en esta condición en la tragedia de Mocoa.

2. La responsabilidad en el ámbito interno e internacional Estado colombiano por su accionar activo u omisivo en la generación de desplazados forzados ambientales, es evidente y plausible de ser judicializado, pues existe un pleno desconocimiento de la normatividad que regula la protección ambiental y la prevención de riesgos de desastres.

3. Es posible pese a no encontrarse en el mismo plano factual, proponer como sujeto de derechos a la protección, conservación, mantenimiento, restauración y no 
ocupación, a las fuentes hídricas que recuperaron su cauce natural en el evento de la avenida fluvio-torrencial de Mocoa, tomando la ratio decidendi de la sentencia T-622 de 2016 de la Honorable Corte Constitucional, logrando se tomen medidas conducentes a recuperar el cauce natural y evitar el asentamiento de poblaciones.

\section{BIBLIOGRAFÍA.}

«Desplazados medioambientales Una nueva realidad», Cuadernos Deusto de Derechos Humanos Núm. 66

JIMÉNEZ C. y SOLEDAD J. (2011), « Los desplazados ambientales, más allá del cambio climático. Un debate abierto», Cuadernos Geográficos, 49 (2011-2), 201-215

OETZEL R. y RUIZ S. (2017), « Movilidad humana, desastres naturales y cambio climático en América Latina. de la comprensión a la acción» recuperado de: https://environmentalmigration.iom.int/sites/default/files/publications/MOVILIDAD\%20Y\%2 0DESASTRES\%20FIN\%20V4.pdf

CORPORACION PARA EL DESARROLLO SOSTENIBLE DEL SUR DE LA AMAZONIACORPOAMAZONIA (2017), « Memoria Técnica Mapa de Delimitación de Avenida Fluvio Torrencial de Mocoa 31 de marzo y 1 de abril de 2017, CORPOMAZONIA recuperado de: http://www.corpoamazonia.gov.co/ 